\title{
Adsorption Behavior and Corrosion Inhibition Mechanism of Three Amino Acids on Mild Steel in 3.5\% NaCl Solution: Electrochemical and Computational Studies
}

\author{
Dong Han ${ }^{1}$, Jiarun $\mathrm{Li}^{2}$, Ning Wang ${ }^{2}$, Kai Wan ${ }^{1, *}$ \\ ${ }^{1}$ Gaomi Campus of Qingdao University of Science and Technology, Gaomi 261500, Shandong, PR \\ China. \\ ${ }^{2}$ Key Laboratory of Marine Environmental Corrosion and Bio-fouling, Institute of Oceanology, \\ Chinese Academy of Sciences, Qingdao 266071, Shandong, PR China. \\ *E-mail: wank@qust.edu.cn.
}

doi: $10.20964 / 2020.10 .30$

Received: 1 June 2020 / Accepted: 29 July 2020 / Published: 31 August 2020

\begin{abstract}
The adsorption behavior and corrosion inhibition mechanism of three amino acids have been studied by using weight loss, electrochemical test, scanning electron microscope, quantum chemical calculation and molecular dynamics simulation techniques. Gravimetric and electrochemical results showed the inhibition efficiencies both increased with the increasing L-arginine and L-lysine concentration from 1.0 $\mathrm{g} \cdot \mathrm{L}^{-1}$ to $10.0 \mathrm{~g} \cdot \mathrm{L}^{-1}$, the maximum inhibition efficiency $74.1 \%$ and $69.1 \%$ was obtained, respectively. However, the inhibition efficiency changed slightly with the increasing concentration of L-histidine. The adsorption behaviors of three amino acids obeyed the Langmuir isotherm and more details were given by theoretical calculation.
\end{abstract}

Keywords: Neutral inhibition, Mild steel, Amino acids , Weight loss, EIS, Modelling study

\section{$\underline{\text { FULL TEXT }}$}

(C) 2020 The Authors. Published by ESG (www.electrochemsci.org). This article is an open access article distributed under the terms and conditions of the Creative Commons Attribution license (http://creativecommons.org/licenses/by/4.0/). 